\title{
Sifat Mekanik Beton Mutu Tinggi Dengan Kombinasi Slag Nikel Dan Slag Baja
}

\author{
Yoel Lian Tiranda ${ }^{* 1}$ Herman Parung ${ }^{* 2}$, Desi Sandy *3 \\ *1 Mahasiswa Program Studi Teknik Sipil, Universitas Kristen Indonesia Paulus, Makassar \\ Email yoelliantiranda@gmail.com
}

*2 Dosen Program Studi Teknik Sipil, Universitas Kristen Indonesia Paulus, Makassar

Email parungherman@gmail.com

*3 Dosen Program Studi Teknik Sipil, Universitas Kristen Indonesia Paulus, Makassar

Email sandymylife@yahoo.co.id

\begin{abstract}
ABSTRAK
Guna meminimalisir terjadinya penumpukan, pemanfaatan limbah slag sangat diperlukan sebagai bahan subtitusi dalam campuran beton. Penelitian ini dimaksudkan untuk mengetahui komposisi campuran beton, kekuatan beton serta perbandingan kekuatan beton dengan kombinasi slag nikel dan slag baja sebagai bahan subtitusi agregat halus dan agregat kasar. Prosentase penggunaan limbah slag nikel sebesar $50 \%$ sebagai bahan subtitusi agregat halus dan limbah slag baja bervariasi dari $0 \%, 15 \%$, dan $30 \%$ sebagai bahan subtitusi agregat kasar pada campuran beton mutu tinggi (f'c = $42 \mathrm{MPa}$ ). Dalam penelitian ini mix design menggunakan metode SNI 03-2834-200. Benda uji yang dipakai berupa silinder dengan dimensi diameter 15 centimeter dengan tinggi 30 centimeter sejumlah 36 benda uji dan balok dengan ukuran $15 \times 15 \times 60$ sebanyak 9 buah. Pengujian yang dibuat dalam variasi umur 7 hari, 21 hari, dan 28 hari. Berdasarkan sifat mekanik beton rata-rata menggunakan limbah slag baja sebagai subtisusi pada variasi $30 \%$ diperoleh hasil terbesar masing-masing 45,27 MPa, 4,91 MPa dan 5,09 MPa untuk nilai kuat tekan, kuat tarik belah dan kuat lentur beton.
\end{abstract}

Kata Kunci: slag nikel, slag baja, beton mutu tinggi, sifat mekanik beton.

\begin{abstract}
This study is intended to determine the composition of the concrete mixture, the strength of the concrete and the ratio of the strength of the concrete with the combination of nickel slag and steel slag as a substitute for fine aggregate and coarse aggregate. The percentage of use of nickel slag waste of $50 \%$ as a substitute for fine aggregate and steel slag waste varies from $0 \%, 15 \%$, and $30 \%$ as a substitute for coarse aggregate in high quality concrete mixtures (f'c $=42 \mathrm{MPa}$ ). In this study, the mix design uses the SNI 03-2834-200 method. The specimens used were 36 cylinders with a diameter of 15 centimeters and a height of 30 centimeters and 9 beams with a size of $15 \times 15 \times 60$. Tests made in 7 days, 21 days, and 28 days age variations. Based on the mechanical properties of the average concrete using steel slag waste as a substitution at $30 \%$ variation, the greatest results were 45.27 MPa, 4.91 MPa and 5.09 MPa respectively for compressive strength, split tensile strength and concrete flexural strength.
\end{abstract}

Keywords: nickel slag, steel slag, high strength concrete, mechanical properties of concrete

\section{PENDAHULUAN}

Adanya aktivitas industri yang semakin beragam mengakibatkan limbah yang diproduksi terus menumpuk. Bidang industri yang semakin maju perkembangannya saat ini yaitu industri nikel dan baja. Dengan bertambahnya aktivitas industri nikel dan baja sehingga limbah yang dihasilkan oleh industri tersebut semakin meningkat pula. Oleh karena itu slag harus dikelola dengan baik sehingga tidak berdampak buruk terhadap lingkungan.

Banyak inovasi penelitian dibidang teknologi material untuk komponen struktur, salah satunya beton. Telah banyak pemanfaatan limbah industri yang dipakai dalam campuran beton, diantaranya yaitu slag. Secara visual, bentuk fisik dari slag nikel yang halus menyerupai pasir yang biasa digunakan sebagai agregat dalam campuran beton.

Beton mutu tinggi merupakan beton yang mempunyai kuat tekan diatas beton normal. SNI 036468-2000 mengartikan beton mutu tinggi sebagai beton dengan kuat tekan yang disyaratkan lebih besar sama dengan $42 \mathrm{MPa}$ [1]. Secara umum, semakin tinggi nilai FAS semakin kecil nilai mutu beton [2] dan FAS bisa juga didefinisikan sebagai berat air terhadap berat total semen dan aditif comentious yang umumnya di tambahkan pada campuran beton mutu tinggi [3]. Biasanya agregat halus yang memiliki modulus halus butiran (MHB) 
antara 1,50-3,8 pada dasarnya menjadikan beton bermutu tinggi. [4]

Khosama (1997), melakukan penelitian dengan menggunakan slag nikel sebagai agregat pada beton mutu tinggi. [5] Dengan beberapa prosentase slag nikel yaitu $0 \%, 50 \%$, dan $70 \%$ dari berat agregat halus. Pengujian ini memakai benda uji silinder $(15 \times 30 \mathrm{~cm})$ sejumlah 36 silinder dengan mutu beton rencana yaitu f'c $30 \mathrm{MPa}$. Hasil penelitian tersebut diperoleh sifat mekanik beton meningkat seiring dengan penambahan prosentase limbah padat (slag nikel) dalam bentuk campuran beton. [6]

Adapun tujuan dari penelitian ini adalah untuk mengetahui komposisi campuran slag nikel sebagai subtitusi agregat halus dan slag baja sebagai bahan subtitusi agregat kasar terhadap campuran beton .

\section{METODE}

Slag nikel diambil dari pabrik PT. Huadi Nickel-Alloy Indonesia, Papanloe, Kecamatan Pa'jakukang, Kabupaten Bantaeng, Sulawesi Selatan dan pengambilan slag baja diperoleh dari pabrik PT. Barawaja, Makassar. Lokasi pengambilan material bias dilihat pada gambar 1 .

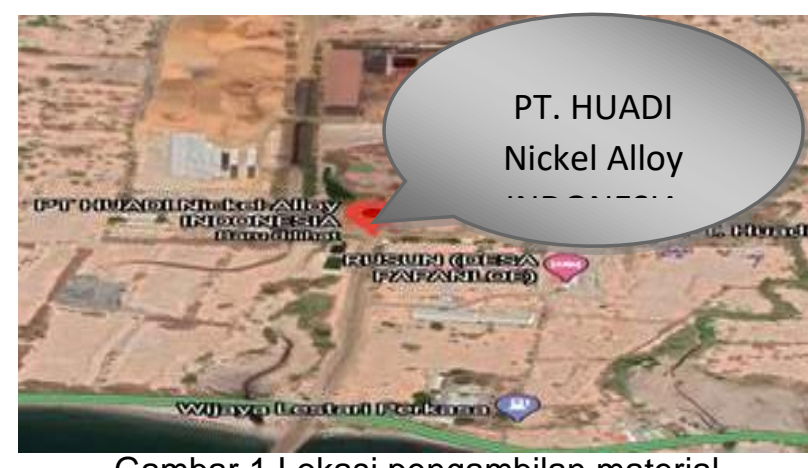

Gambar 1.Lokasi pengambilan material

1. Pemeriksaan Karakteristik Agregat

Tabel 1. Sifat agregat kasar

\begin{tabular}{lc}
\hline \multicolumn{1}{c}{ Sifat Agregat Kasar } & Hasil \\
\hline Kadar lumpur (\%) & 0,58 \\
Kelembaban (\%) & 0,91 \\
Berat volume padat, Kg/L & 1,60 \\
Berat volume gembur, Kg/L & 1,55 \\
Absorpsi \% & 1,13 \\
Berat jenis (SSD) & 2,657 \\
\hline
\end{tabular}

Tabel 2. Analisa saringan agregat kasar

\begin{tabular}{cccc} 
Nomor saringan & \multicolumn{2}{c}{ Ukuran lubang ayakan } & \multirow{2}{*}{ Spesifikasi SNI ASTM C136-2012 } \\
\cline { 2 - 3 } & $\mathrm{mm}$ & inci & 100 \\
\hline- & 38,10 & 1,5 & 100 \\
- & 25,00 & 1 & $90-100$ \\
- & 19,10 & $3 / 4$ & $55-90$ \\
- & 12,50 & $1 / 2$ & $20-55$ \\
No. 4 & 9,50 & $3 / 8$ & $0-10$ \\
& 4,75 & & 0 \\
\hline & Pan & & \\
\hline
\end{tabular}

\section{Slag Baja}

Tabel 3. Hasil pengujian slag baja

\begin{tabular}{cc}
\hline Karakteristik & Hasil \\
\hline Kadar lumpur, \% & 0,580 \\
Kadar air \% & 0,263 \\
Berat vol. padat (Kg/L) & 1805 \\
Berat vol. gembur (Kg/L) & 1625 \\
Absorpsi \% & 1,215 \\
Berat jenis (SSD) & 2,643 \\
\hline
\end{tabular}

Tabel 4. Analisa saringan agregat halus

\begin{tabular}{|c|c|c|c|}
\hline \multirow{2}{*}{$\begin{array}{c}\text { Nomor } \\
\text { saringa } \\
\mathrm{n}\end{array}$} & \multicolumn{2}{|c|}{$\begin{array}{l}\text { Ukuran lubang } \\
\text { ayakan }\end{array}$} & \multirow[t]{2}{*}{$\begin{array}{c}\text { Spesifikasi SNI } \\
\text { ASTM C136-2012 }\end{array}$} \\
\hline & $\mathrm{mm}$ & Inci & \\
\hline 4 & 4,75 & - & $95-100$ \\
\hline 8 & 2,38 & - & $95-100$ \\
\hline 16 & 1,19 & - & $90-100$ \\
\hline 30 & 0,59 & - & $80-100$ \\
\hline
\end{tabular}




\begin{tabular}{cccc}
50 & 0,27 & - & $5-50$ \\
\hline 100 & 0,14 & - & $0-15$ \\
200 & 0,074 & - & $0-5$ \\
& Pan & & 0
\end{tabular}

Tabel 5. Hasil pengujian slag nikel

\begin{tabular}{cc}
\hline Karakteristik & Hasil \\
\hline Kelembaban & $0,1 \%$ \\
Kadar Organik & No.1 \\
Kadar Lumpur & $0,9 \%$ \\
Berat Jenis SSD & 2,941 \\
Absorpsi (Penyerapan) & $0,908 \%$ \\
Berat Volume Padat & $1758 \mathrm{~kg} / \mathrm{m}^{3}$ \\
Berat Volume Gembur & $1673,33 \mathrm{~kg} / \mathrm{m}^{3}$ \\
Modulus Kehalusan & 2,600 \\
\hline
\end{tabular}

3. Pemeriksaan Karakteristik Beton

a. Kuat Tekan Beton

Kuat tekan beton merupakan besarnya beban per satuan luas[7].

Nilai kuat tekan beton didapatkan dengan cara standar, dengan memakai mesin uji dan pembebanan tekan sedikit demi sedikit terhadap benda uji beton (diameter $15 \mathrm{~cm}$, tinggi $30 \mathrm{~cm}$ ) hingga hancur [8]. Pengecekan nilai kuat tekan beton memakai persamaan (1):

$\mathrm{f}^{\prime}{ }_{\mathrm{c}}=\frac{\mathrm{P}}{\mathrm{A}}$

Sistem uji kuat tekan beton dapat ditinjau pada Gambar 2.

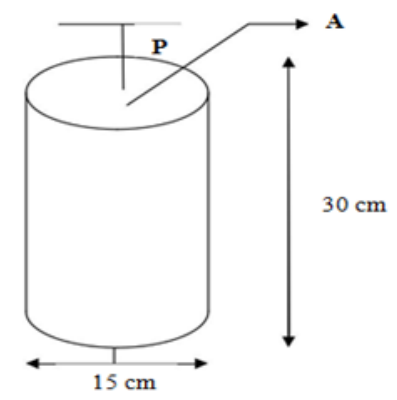

Gambar 2. Uji kuat tekan

\section{b. Kuat Tarik Belah Beton}

Kuat tarik belah merupakan kuat tarik beton yang dipengaruhi menurut kuat tarik belah berdasarkan benda uji beton yang ditekan dengan posisi memanjang. [9]

$$
\mathrm{f}_{\mathrm{t}}=\frac{2 \mathrm{P}}{\pi \mathrm{Ld}}
$$
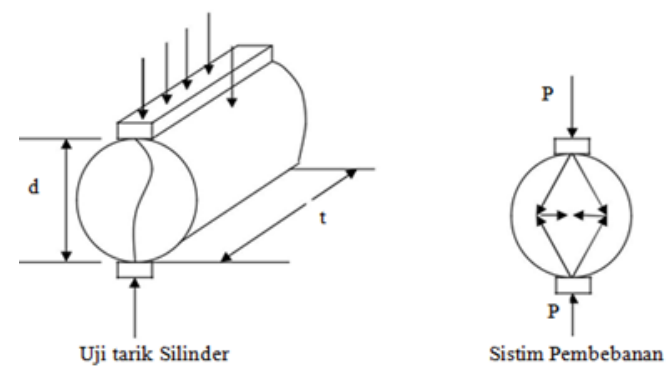

Gambar 3. Uji tarik belah

c. Kuat Lentur Beton

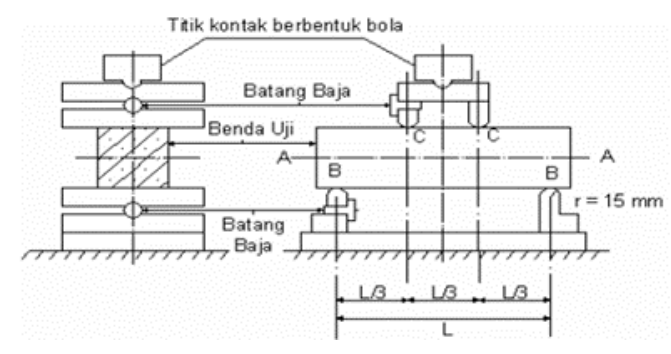

Gambar 4. Benda uji kuat lentur, tata letak dan pembebanan

$f_{r}=\frac{P \times L}{b \times h^{2}}$

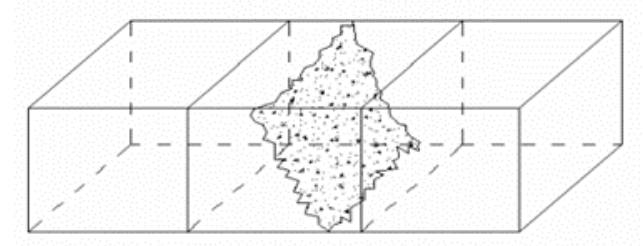

Gambar 5. Cara uji kuat lentur saat keruntuhan di tengah bentang

$$
f_{r}=\frac{\mathrm{Pxa}}{\mathrm{bxh}^{2}}
$$

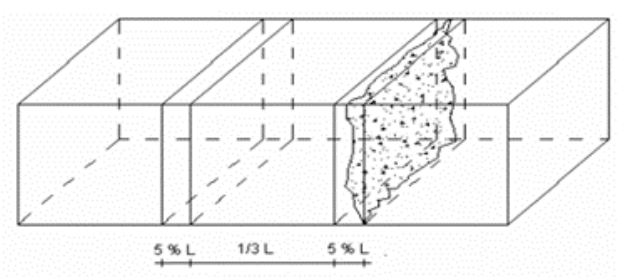

Gambar 6. Cara uji kuat lentur dengan keruntuhan di luar tengah bentang 
4. Pemeriksaan Berat Jenis Filler

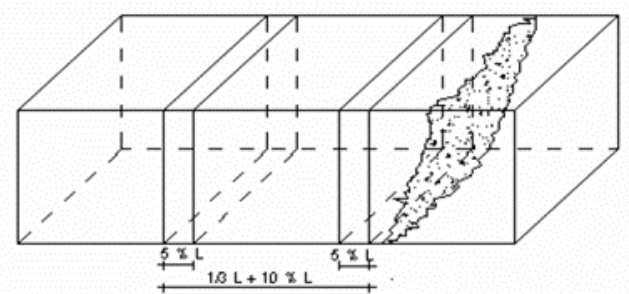

Gambar 7. Patahan di luar $1 / 3$ bentang tengah dan garis patah ( $>5 \%$ dari bentang)
Tabel 7. Hasil rekapitulasi uji berat jenis Filler

\begin{tabular}{cccc}
\multicolumn{1}{c}{ Sifat } & Hasil & $\begin{array}{c}\text { 3atas Interval } \\
\text { SNI }\end{array}$ & Keterangan \\
\hline $\begin{array}{l}\text { Berat Jenis } \\
\text { Semen }\end{array}$ & 3,15 & $3-3,2$ & Memenuhi \\
\hline
\end{tabular}

5. Mix Design dengan Metode SNI 03-2834-2000

Tabel 8. Komposisi kebutuhan bahan campuran beton untuk $1 \mathrm{~m}^{3}$

\begin{tabular}{crcccccc}
\hline $\begin{array}{c}\text { Subtitusi } \\
\text { S.Baja }\end{array}$ & Semen & Air & Agregat Kasar & s. Baja & Ag. Halus & S. Nikel & $\begin{array}{c}\text { Sicament } \\
\text { LN }\end{array}$ \\
\hline $0 \%$ & 525 & 210 & 929,7 & 0 & 336,6 & 360,2 & 2,1 \\
$15 \%$ & 525 & 210 & 790,3 & 150,6 & 336,6 & 360,2 & 2,1 \\
$30 \%$ & 525 & 210 & 650,8 & 301,2 & 336,6 & 360,2 & 2,1 \\
\hline
\end{tabular}

\section{HASIL DAN PEMBAHASAN}

1. Karakteristik Material

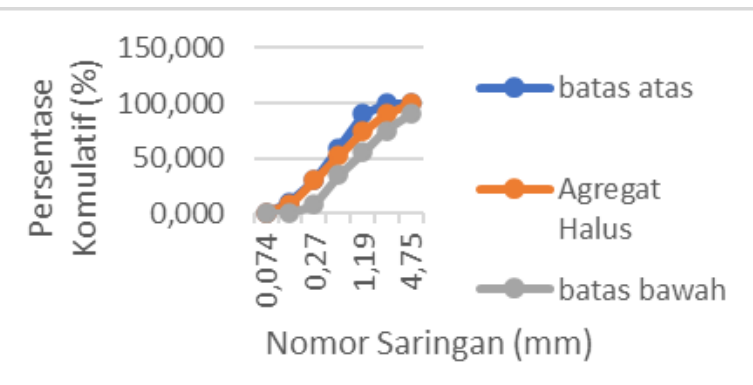

Gambar 8. Analisa saringan agregat kasar

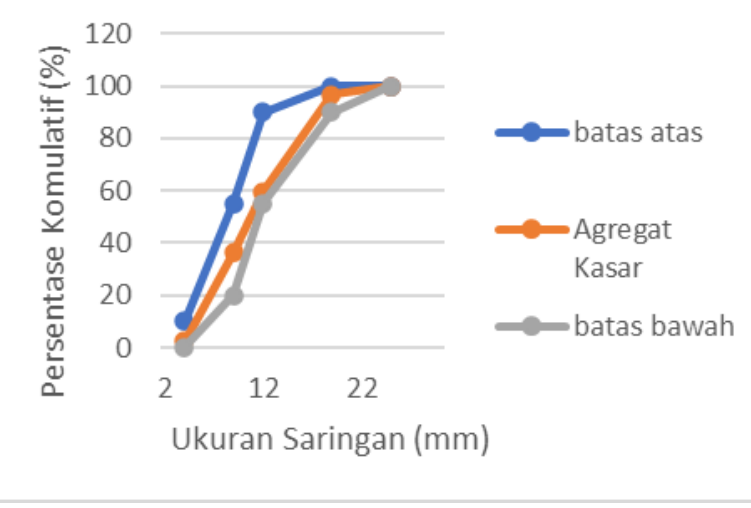

Gambar 9. Analisa saringan agregat halus

2. Hasil Pemeriksaan Kuat Tekan Beton

Tabel 9. Kuat tekan (slag baja 0\%)

\begin{tabular}{cccccc} 
Subtitusi Slag Umur (Hari) & $\begin{array}{c}\text { Beban Maksimum } \\
(\mathrm{KN})\end{array}$ & $\begin{array}{c}\text { Kuat Tekan } \\
\text { Beton tiap } \\
\text { sampel (Mpa) }\end{array}$ & $\begin{array}{c}\text { Kuat Tekan } \\
\text { Beton (Mpa) }\end{array}$ & $\begin{array}{c}\text { Konversi 28 hari } \\
\text { (Mpa) }\end{array}$ \\
\hline & 7 & 500 & 28,294 & & \\
& & 470 & 26,597 & 27,540 & 42,369 \\
Nikel 50\%+ & 21 & 790 & 27,728 & & \\
Baja 0\% & 710 & 41,875 & & 43,087 \\
& & 720 & 40,178 & 40,932 & \\
& 28 & 770 & 40,744 & & 43,762 \\
\hline
\end{tabular}


Tabel 10. Kuat tekan (slag baja 15\%)

\begin{tabular}{cccccc}
\hline Subtitusi Slag Umur (Hari) & $\begin{array}{c}\text { Beban Maksimum } \\
(\mathrm{KN})\end{array}$ & $\begin{array}{c}\text { Kuat Tekan } \\
\text { Beton tiap } \\
\text { sampel (Mpa) }\end{array}$ & $\begin{array}{c}\text { Kuat Tekan } \\
\text { Beton (Mpa) }\end{array}$ & $\begin{array}{c}\text { Konversi 28 hari } \\
\text { (Mpa) }\end{array}$ \\
\hline & 7 & 480 & 27,162 & & \\
& & 490 & 27,728 & 28,106 & 43,239 \\
Nikel 50\%+ & 21 & 720 & 29,426 & & \\
Baja 15\% & 750 & 42,441 & & 43,881 \\
& & 740 & 41,875 & 41,687 & \\
& 28 & 780 & 40,744 & & 44,516 \\
\hline
\end{tabular}

Tabel 11. Kuat tekan (slag baja 30\%)

\begin{tabular}{cccccc}
\hline Subtitusi Slag & Umur (Hari) & $\begin{array}{c}\text { Beban Maksimum } \\
(\mathrm{KN})\end{array}$ & $\begin{array}{c}\text { Kuat Tekan } \\
\text { Beton tiap } \\
\text { sampel (Mpa) }\end{array}$ & $\begin{array}{c}\text { Kuat Tekan } \\
\text { Beton (Mpa) }\end{array}$ & $\begin{array}{c}\text { Konversi 28 hari } \\
(\mathrm{Mpa})\end{array}$ \\
\hline & 7 & 530 & 29,992 & & \\
& & 510 & 28,860 & 29,049 & 44,690 \\
Nikel 50\%+ & 21 & 500 & 28,294 & & \\
Baja 30\% & & 770 & 43,573 & & 45,072 \\
& & 750 & 42,441 & 42,819 & \\
& 28 & 750 & 42,441 & & 45,271 \\
\hline
\end{tabular}

3. Hasil Uji Kuat Tarik Belah Beton

Tabel 12. Kuat tarik belah beton

\begin{tabular}{|c|c|c|c|c|}
\hline \multicolumn{2}{|c|}{ Variasi Slag } & \multirow{2}{*}{$\begin{array}{l}\text { Kuat Tarik Belah Aktual } \\
\text { (KN) }\end{array}$} & \multirow{2}{*}{$\begin{array}{l}\text { Kuat Tarik Belah Aktual } \\
\text { Rata-rata (Mpa) }\end{array}$} & \multirow{2}{*}{$\begin{array}{c}\text { Kuat Tarik Belah } \\
\text { Aktual Rata-rata } \\
\text { (Mpa) }\end{array}$} \\
\hline Nikel (\%) & Вaja (\%) & & & \\
\hline \multirow{4}{*}{50} & \multirow[t]{3}{*}{ 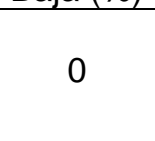 } & 240 & 3,397 & \multirow{4}{*}{3,397} \\
\hline & & 230 & 3,255 & \\
\hline & & 250 & 3,539 & \\
\hline & \multirow{4}{*}{15} & 300 & 4,246 & \\
\hline \multirow[t]{3}{*}{50} & & 310 & 4,388 & \multirow[t]{3}{*}{4,199} \\
\hline & & 280 & 3,963 & \\
\hline & & 350 & 4,954 & \\
\hline \multirow[t]{2}{*}{50} & \multirow[t]{2}{*}{30} & 370 & 5,096 & \multirow[t]{2}{*}{4,907} \\
\hline & & 330 & 4,671 & \\
\hline
\end{tabular}

4. Hasil Pemeriksaan Kuat Lentur

Tabel 13. Kuat lentur beton

\begin{tabular}{ccccc}
\hline $\begin{array}{c}\text { Variasi Slag } \\
(\%)\end{array}$ & $\begin{array}{c}\text { Beban Maksimum } \\
(\text { Ton) }\end{array}$ & $\begin{array}{c}\text { Beban Maksimum } \\
(\mathrm{KN})\end{array}$ & $\begin{array}{c}\text { Kuat Lentur } \\
\text { Beton (Mpa) }\end{array}$ & $\begin{array}{c}\text { Kuat Lentur Beton } \\
\text { Aktual Rata-rata } \\
(\mathrm{Mpa})\end{array}$ \\
\hline
\end{tabular}




\begin{tabular}{ccccc}
\hline Nikel $50 \%+$ & 2,2 & 21,582 & 3,325 & \\
Baja 0\% & 2,3 & 22,563 & 3,476 & 3,224 \\
& 1,9 & 18,639 & 2,872 & \\
Nikel $50 \%+$ & 2,4 & 23,544 & 3,628 & 4,131 \\
Baja 15\% & 2,8 & 27,468 & 4,232 & \\
& 3 & 29,430 & 4,534 & \\
Nikel 50\%+ & 3,4 & 33,354 & 5,139 & 5,089 \\
Baja 30\% & 3,6 & 35,316 & 5,441 & \\
\hline
\end{tabular}

Tabel 14. Data pengujian kuat tekan beton

\begin{tabular}{ccc}
\hline Subtitusi Slag (\%) & Umur (Hari) & Kuat Tekan Beton (Mpa) \\
\hline Nikel 50\% + Baja 0\% & 7 & 27,540 \\
& 21 & 40,932 \\
Nikel 50\% + Baja 15\% & 28 & 43,762 \\
& 7 & 28,106 \\
Nikel 50\% + Baja 30\% & 21 & 41,687 \\
& 28 & 44,516 \\
& 7 & 29,049 \\
& 21 & 42,819 \\
\hline
\end{tabular}

\section{KUAT TEKAN vs UMUR BETON}
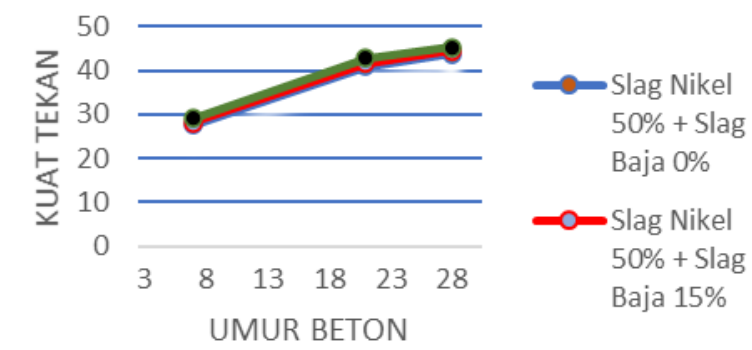

Gambar 10. Hubungan antara umur beton dengan kuat tekan beton

Tabel 15. Data pengujian kuat tekan beton

\begin{tabular}{cc}
\hline Variasi Slag (\%) & $\begin{array}{c}\text { Kuat Tekan Beton } \\
(\mathrm{Mpa})\end{array}$ \\
\hline Nikel 50\% + Baja 0\% & 43,762 \\
Nikel 50\% + Baja 15\% & 44,516 \\
Nikel 50\% + Baja 30\% & 45,271 \\
\hline
\end{tabular}

\section{PROSENTASE SLAG VS KUAT} TEKAN

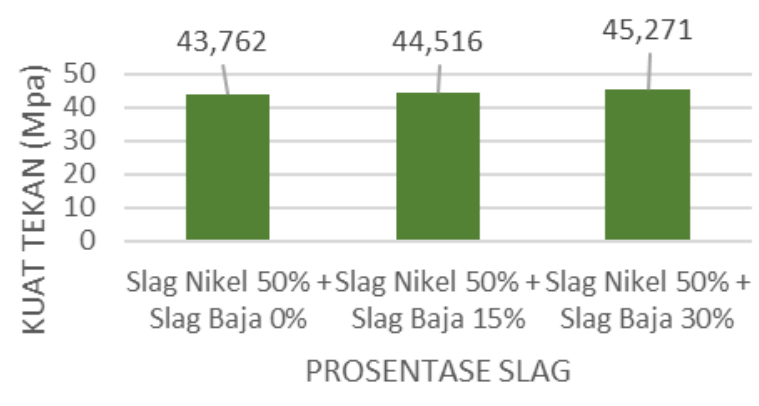

Gambar 11. Hubungan antara prosentase slag dengan kuat tekan

Dari gambar 11. diketahui kuat tekan beton mengalami peningkatan dengan penambahan subtitusi slag baja sampai pada variasi $30 \%$.

Tabel 16. Kuat tarik belah beton

\begin{tabular}{cc}
\hline Prosentase Slag & Hasil (MPa) \\
\hline Nikel 50\% + Baja 0\% & 3,397 \\
Nikel 50\% + Baja 15\% & 4,199 \\
Nikel 50\% + Baja 30\% & 4,907 \\
\hline
\end{tabular}




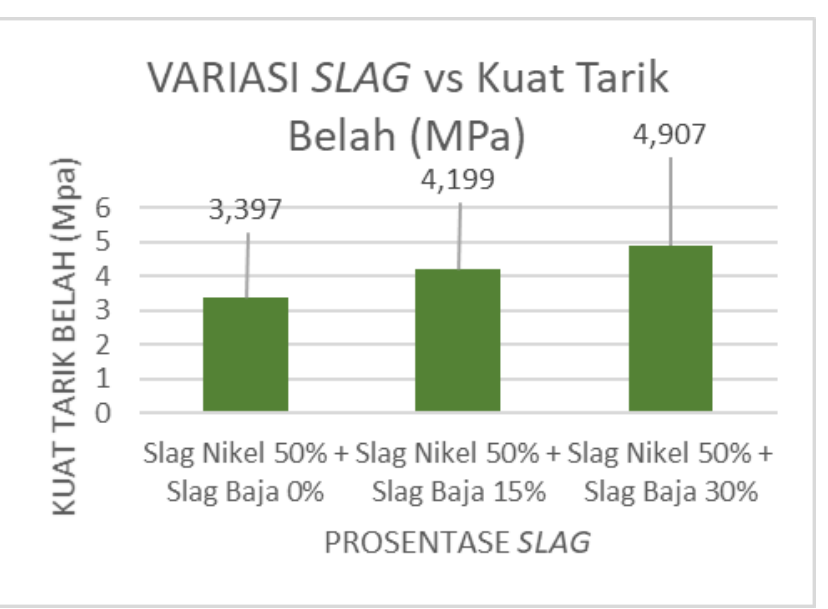

Gambar 12. Hubungan antara prosentase slag dengan kuat tarik belah

Dari hasil pengujian diperoleh nilai kuat tarik belah terendah berada pada variasi subtitusi slag baja sebesar $0 \%$ dan nilai tertinggi berada pada variasi subtitusi slag baja sebesar $30 \%$.

Tabel 17. Kuat lentur beton

\begin{tabular}{rc}
\hline Variasi Slag Baja (\%) & Kuat Lentur (MPa) \\
\hline Nikel 50\% + Baja 0\% & 3,224 \\
Nikel 50\% + Baja 15\% & 4,131 \\
Nikel 50\% + Baja 30\% & 5,089 \\
\hline
\end{tabular}

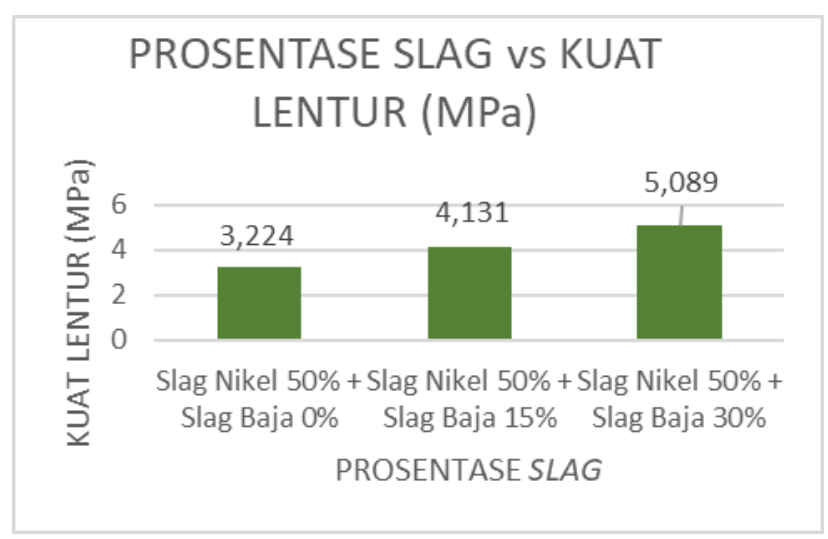

Gambar 13. Hubungan antara slag dengan kuat lentur

Dari gambar 13 dapat diketahui kaitan prosentase slag dengan kuat lentur beton, yaitu dengan semakin tinggi prosentase slag maka nilai kuat lentur yang dialami beton semakin besar. Dari hasil penelitian yang dilakukan nilai kuat lentur tertinggi berada pada subtitusi slag baja sebesar $30 \%$ dan nilai terendah berada pada subtitusi slag baja sebesar $0 \%$.
Tabel 18. Perbandingan antara kuat tekan dan kuat tarik belah beton

\begin{tabular}{ccc}
\hline & & Perbandingan \\
\cline { 3 - 3 } $\begin{array}{c}\text { Kuat } \\
\text { Tekan } \\
\left(f^{\prime} c\right)[\mathrm{MPa}]\end{array}$ & $\begin{array}{c}\text { Kuat Lentur }\left(f^{\prime} t\right) \\
{[\mathrm{MPa}]}\end{array}$ & $\frac{f t}{f^{\prime} c} \times 100 \%$ \\
\hline 43,762 & & 0,487 \\
44,516 & 3,397 & 0,619 \\
45,271 & 4,199 & 0,756 \\
\hline
\end{tabular}

Tabel 19. Perbandingan kuat tekan dengan kuat lentur

\begin{tabular}{cccc}
\hline & & \multicolumn{2}{c}{ Perbandingan } \\
\cline { 3 - 4 } $\begin{array}{c}\text { Kuat Tekan } \\
\left(f^{\prime} c\right)[\mathrm{MPa}]\end{array}$ & $\begin{array}{c}\text { Kuat } \\
\text { Lentur }\left(f^{\prime} t\right) \\
{[\mathrm{MPa}]}\end{array}$ & $\sqrt{f^{\prime} c}$ & $\frac{f_{r}}{\sqrt{f^{\prime} c}}$ \\
\hline 43,762 & 3,224 & 6,615 & 0,487 \\
44,516 & 4,131 & 6,672 & 0,619 \\
45,271 & 5,089 & 6,728 & 0,756 \\
\hline
\end{tabular}

\section{KESIMPULAN}

Dari mix design didapatkan perbandingan antara semen, agregat halus, agregat kasar, slag nikel, dan slag baja yaitu:Slag Baja $0 \%=$ semen (1) : Slag Nikel $(0,68)$ : Agregat Halus $(0,64)$ : Agregat Kasar $(1,77)$ : Slag Baja (0), Slag Baja 15\% = semen (1) : Slag Nikel $(0,68)$ : Agregat Halus $(0,64)$ : Agregat Kasar $(1,51)$ : Slag Baja $(0,29)$, Slag Baja $30 \%=$ semen (1) : Slag Nikel $(0,68)$ : Agregat Halus $(0,64)$ : Agregat Kasar $(1,24)$ : Slag Baja $(0,57$. Nilai maksimal kuat tekan, kuat tarik belah, dan kuat lentur beton terjadi pada saat komposisi slag nikel 50\% dan slag baja $30 \%$.

Pengaruh subtitusi slag baja pada variasi $15 \%$ dan $30 \%$ mengalami peningkatan sifat mekanik beton.

\section{DAFTAR PUSTAKA}

[1] SNI 03-6468-2000, Tata Cara Perencanaan Campuran Tinggi degan Semen Portland dengan Abu Terbang. Jakarta: Badan Standardisasi Nasional, 2000.

[2] T. Mulyono, 2004, Teknologi Beton. Yogjakarta: Andi 
[3] S. F.X., 1998, Beton Berkinerja Tinggi, Keunggulan dan Permasalahannya. Jakarta: Seminar HAKI

[4] L. F.de, 1990, A Method for proportioning high strength concrete, vol. 12. Cement: Concrete and Aggregates

[5] Sugiri, S., Khosama, L.K., 1997, Penggunaan Terak Nikel sebagai Agregat pada Beton Mutu Tinggi. Institut Teknologi Bandung: Tesis Program Magister

[6] I. Tandi, 2019, "Pengaruh Slag Nikel Sebagai Bahan Pengganti Agregat Halus Terhadap Kuat Tekan, Kuat Tarik Belah, dan Modulus Elastisitas Beton," Jur. Tek. Sipil Fak. Tek. Univ. Kristen Indones. Paulus Makassar Sulawesi Selatan
[7] SNI 1974-2011, Cara Uji Tekan Beton Dengan Benda Uji Silinder. Jakarta: Badan Standarisasi Nasional, 2011.

[8] D. Istimawan, 2003, Manajemen Proyek Dan Konstruksi, Jilid 2. Yogjakarta: Kanisius

[9] SNI 03-2491-2002, Metode Pengujian Kuat Tarik Belah Beton. Bandung: Badan Standarisasi Nasional, 2002.

[10] SNI 03-4431-2011, Cara Uji Kuat Lentur Beton Normal dengan Dua Titik Pembebanan. Jakarta: Badan Standarisasi Nasional, 2011. 